\title{
An Investigation Of Strategic Decision Making In Service Marketing Through Case Study Development And Analysis
}

Joseph L. Rosetti, Siena College, USA

Meghan Maceiko, Siena College, USA

\begin{abstract}
Through the collaborative efforts of an undergraduate student and a professor of marketing, this paper focuses on a case study and corresponding teaching notes developed as a final component of an independent study in service marketing. The case utilizes the hospitality industry as the template for analysis of the appropriateness of marketing strategies in a growth industry with a corresponding high level of embedded competition. The paper demonstrates how the professor utilized the development of the case study as a pedagogical methodology to provide the independent study student with a transition to the higher levels of a learning taxonomy while simultaneously developing a comprehensive evaluation instrument to foster a higher level of learning for students enrolled in the introductory undergraduate marketing course.
\end{abstract}

Keywords: case analysis, product mix, target marketing, product positioning.

\section{INTRODUCTION}

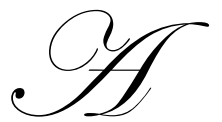

11 The Details case study which is the primary focus of this paper was the final component of a 3 credit hour independent study course taken by an undergraduate student investigating service marketing. The student demonstrated a specific career objective in the event planning segment of the hospitality industry. Since, the marketing curriculum did not specifically include a direct course designed for service marketing analysis this independent study provided the student with an opportunity to conduct an investigation at a level of both breadth and depth which otherwise would not have been available.

The student was initially required to engage in a series of readings designed to develop a theoretical background in service marketing, and the event planning segment within the hospitality industry. As the student progressed through the readings and corresponding assignments each were analyzed through an instructor/student seminar oriented pedagogy. The student was then asked to develop a service marketing case study utilizing the event planning segment as the template for analysis of marketing strategies in a growth industry with a corresponding high level of embedded competition. Under the guidance of the professor, the collaborative development of the case study, and corresponding teaching notes provided the student with the challenge to complete the independent study beyond the initial knowledge and comprehension level of a classic learning taxonomy through the application, analysis, and synthesis of the applicable marketing theory within the service sector environment. Simultaneously, and the focus of this paper, an evaluation instrument was designed and developed to foster a higher level of learning for students enrolled in the introductory undergraduate marketing course (Bloom 1956).

\section{CASE STUDY AND TEACHING NOTES DEVELOPMENT PROCESS}

Once the student completed the readings and assignments described above, a review of the syllabus from the introduction to marketing course, which the student previously took from the collaborating professor, was undertaken. Simultaneously, the professor and student reviewed the topics of the service marketing readings and 
analyzed the degree to which there were direct topical correlations. Those correlations were actually predetermined from the introduction to marketing syllabus by the instructor to establish the focus of the readings in the more focused context of the event planning sector of service marketing. The student was then informed that these topics would serve as the basic content elements of the case study and corresponding teaching notes which would be developed. These are identified as items 1 through 7 in the student report components of the teaching notes. The student was then supplied with two short cases which had been utilized as grading elements in the introduction to marketing course, and a collaborative review of them were conducted in the context of how those 7 content items were incorporated for student application and analysis at the introduction to marketing course level.

The professor then provided the student with the italicized words in the four items described in the teaching notes as case analysis methodology and instructions. The student was familiar with these from the introduction to marketing course and only a brief review was required.

Utilizing the product life cycle as the dominant framework from which to provide guidance, the professor informed the student that a case scenario was to be developed in the event planning industry for a fictional small regional business. Additionally, the student was asked to place the business in the growth stage of the product life cycle with a product mix which included 3 to 4 product lines and a range of 3 to 4 primary competitors. Once again, the case analysis format utilized in the principles of marketing course was utilized as the reference point. In that course a team based approach was implemented for case study analysis. The professor and student then reviewed the challenges that team members had when attempting to resolve a particular strategic issue. To provide a level of focus during the case design process, the student was informed that the dominant issue to be resolved would be to determine the most appropriate means to enhance market share. As a guide to develop this concept, the student was provided with a framework suggesting she describe the current company owner(s), the products they marketed, their current market share, who their competitors were and their corresponding products and market share in the case scenario. Finally, the student was asked to develop and include three distinct strategic options suggested by either managers or owners of the company, at a level appropriate for analysis by an introduction to marketing student audience serving as a consulting firm hired to analyze the recommended strategies..

The student then independently developed a series of drafts which were collaboratively analyzed in the dual context of the two previously described elements of the teaching notes. At each level of case revision, the steps in the two major elements of the teaching notes were then developed in the specific context of the case. Finally, the issues in the teaching notes relative to the nature of providing student guidance for the introduction to marketing students throughout their analysis and report development were created. This was accomplished through a candid discussion between the authors regarding the strengths and weaknesses of the instructions the student had received from the collaborating professor when conducting her own first level case analysis in the introduction to marketing class.

\section{ALL THE DETAILS-CASE STUDY}

All the Details Inc., established in 2000, was founded by two childhood friends from Long Island, New York. Both founders were passionate about the entertainment business. Details is a full service marketing company whose goal is to promote special events, such as weddings, engagements, and birthdays.

Details strives to continually develop a consumer driven product mix by attaining client relationships through access and utilization of today's most popular trends and lifestyles. In turn, they seek to create and use innovative work to deliver a quality event.

Erin Mitchlee, CEO of Details, is one of the most sought after event planners on Long Island. Known for her creative ideas, her exceptional attention to detail is what satisfies her clients beyond their expectations. Her bubbly personality and calm demeanor is what helps her clients feel at ease when she and her partner/COO, Tina Basilice, create a perception of one-of-a-kind events through unique and distinctive design.

Mitchlee began her career in the special events business more than 15 years ago by creating custom invitations for social events. Her inspiration and creativity led Erin to expand her talents into party planning. 
Mitchlee and her childhood best friend, Tina Basilice, made invitations out of the basement of Tina's house for months. The demand was more than they could handle. This prompted them to pursue the idea of starting a business together which they took as a complete risk and have developed into a successful service marketing business.

Basilice has been working alongside Mitchlee for the past 15 years. Tina's organizational skills and fun sense of humor add to the calm demeanor at Details. Her extensive experience and attention to detail and style have contributed considerably to their success.

Their primary target market has been for events on Long Island with a very limited secondary market reach throughout the five boroughs (Bronx, Brooklyn, Manhattan, Queens and Staten Island) and the primary focus is to the upper middle family income levels.

Their range of products include: weddings, birthdays, and engagements. For each of these the following activities are available: music, transportation service, and food.

Details would like to continue to grow and expand. As a first step, Details hired a marketing research firm to investigate the feasibility of doing so. The research conducted by this independent company indicates that there is room for expansion in the market because of the growth stage of the products at the industry level. Details did not hire the company to determine anything beyond this.

Both Erin and Tina are delighted with the good news and immediately began discussions of how to begin the expansion. However, very quickly they found that they have some serious differences of opinions on how to go about this.

Erin Mitchlee is looking to offer more upscale options within the events and would like to partner with companies who will complement their approach to events to achieve this. In other words she would like to expand offerings by partnering with other smaller companies that specialize in particular types of music, transportation services and food offerings for the weddings, birthdays and engagements throughout Long Island. Currently Details supplies all of this internally.

Tina Basilice feels that they should not increase the number of offerings within the events. Instead she believes it would be more appropriate to simply expand the different types of events beyond weddings, birthdays, and engagements. Her idea is to market events for more varied forms of celebrations which revolve around religious or ethnic factors.

They have recently brought their marketing manager of 8 years, Joan Fitzpatrick, into the conversation. Joan believes that the company can increase market share by expanding their territory with primarily the same events and but with lower costs by offering lower priced foods and transportation, and retaining their traditional DJ oriented music. She has indicated that this may require an adjustment of their primary and secondary target markets as well. As an example she has cited that a bulk of 21-30 age bracket college graduates from Long Island with middle-income levels have relocated to the Brooklyn area. This provides an opportunity to live closer to Manhattan where they have recently secured employment but cannot afford to live.

The following is a profile of Details current competition.

- $\quad$ Marriage Bliss specializes in weddings, does some engagements and has $25 \%$ of the total event market in Long Island.

- $\quad$ Blow Out the Candles does birthdays only and has 20\% of the total event market in Long Island.

- You Never Grow Old also specializes in birthdays and has 15\% of the total event market in Long Island.

- Always a Party is the largest in the Long Island area, specializing in weddings, birthdays, engagements, and any other special celebration. They have $30 \%$ of the event market there.

Details has $10 \%$ of the event market in Long Island and would like to increase it to $15-20 \%$ in the next five years. They have no real data regarding competition outside of Long Island. 
You are a friend of Mitchlee, Basilice and Fitzpatrick and have agreed to serve as a consultant to help them resolve their differences of opinions regarding this market expansion. You have recently opened a marketing consulting firm and now you have your first client. It is your role to provide a clear recommendation and take a position that you feel provides the best approach for them.

\section{CASE STUDY TEACHIING NOTES}

\section{Introduction}

This case is intended as a first level application in an introductory marketing course and should be useful to provide a transition from knowledge recall and comprehension to an application level in a learning taxonomy. Given this intended position as a first level application in the course, the case intentionally lacks subject matter breadth by focusing on one element of the marketing mix.

The primary intent is for the student or student groups to focus on using the information in the particular case situation to provide a relationship to the specific range of marketing content. The focus is on the product component of marketing and the corresponding target market issues. However, the case is designed to exclude the specific marketing terminology relative to that content in an effort to have the student or student groups identify those subject matter components in this unique or particular setting.

There is considerable latitude regarding the use of the case in the introductory marketing classroom. The following broad template provides but one possible approach to contribute toward a transition to learning taxonomy application as a learning outcome for the course.

\section{Student Instructions}

The classroom instructor should provide a reading of the case with the students as a first level application and then indicate to the students that their role as the consultants is to develop a report for the company. There are a wide range of options available to the instructor relative to the style of the report. However, it may be helpful for students to develop a formal written report rather than a spontaneous oral report for an initial case experience.

\section{Case Analysis Methodology and Instructions}

To create a report, the students must be aware of the need to follow a logical pattern of decision making. Again, individual instructors will have a sense of student background relative to this process.

The following may be a feasible sequential approach to appeal to a broad range of student backgrounds:

1. Relevant Facts--students should be aware of the material in the case that is factual and seems to have a relationship to the subject matter. Students may not have to incorporate these into the written report. Like step 1, steps 2 and 3 are also designed to help lead to step 4 and may not have to be included in a report for this transition phase in the learning taxonomy. Instead, utilizing steps 2 and 3 may be particularly useful as a stimulant for group discussion if a team approach is utilized.

2. Determine Problem $(s)$--students should be aware that all three of the approaches suggested in the case may have potential problems, which may create barriers to effectively attain objectives relative to this subject matter. Therefore it is their role to analyze what seems to be problematic. In order to do this, the students may need to be reminded that the case subject matter is related to the unit or set of chapters on product and target markets. This obviously may vary depending on individual textbook and other course materials. The instructor may also further indicate which sub sets within the unit to review or to rely on the prior lectures and corresponding student notes relative to this.

3. Develop Possible Alternatives If Appropriate and Analyze Feasibility of Implementation-- as an outgrowth of \# 2 above, the students should begin to develop a level of appropriateness of the three individual approaches to market growth proposed in the case and either choose among them or unravel possible 
alternative solutions. The instructor could consider suggesting to students that they rank the suggestions from the two owners and the marketing manager.

4. Choose a Solution(s) and Justify --instructors may indicate to students that their written report should be focused on the solutions they ultimately recommend for the company utilizing the product and target market subject matter as the justification component. Once again, as a first level application it may be appropriate to offer specific guidance regarding which subject matter would provide a logical basis for the justification of the approach the student(s) recommend.

\section{Student Report Components}

Instructors may recommend to students that the report should provide a specific method for expansion and that the justifications for their recommendations in step 4 should focus on all or instructor selected portions of the following subject matter content:

1. Product Mix Components--the recommendation should be justified utilizing product line and product line assortment terminology. The concept of product mix breadth and depth should be utilized. These terms as previously suggested are not utilized in the case but can be easily identified for both All The Details and their competitors. Another option is to unveil this information as a joint exercise with the instructor. As an example, the instructor could consider identifying the lines (breadth) as the weddings birthdays and engagements and the music, transportation and food as the assortment within the lines (depth).

2. Market Segmentation and or Aggregation including Product Differentiation-- students should discuss this in the context of both breadth and depth for the product lines and assortment within those lines as related to 1 above. In this component of the report students may or may not recognize the impact of the product mix choices to the target market strategy or vice versa.

3. Target Demographics, Geographics, Psychographics, and Behavioral Considerations--depending on the individual instructor approach; these may be combined in terms of the relationship to segmentation and /or aggregation. An alternative is to integrate into the case by probing students on it as an individual component after the case reports have been submitted. As in 1, the case provides an opportunity for the students to discover these issues but this set of specific terminology is excluded. Terms such as upper middle income, age groups and current potential geographic areas are discussed. The instructor may decide how much guidance students should or should not receive relative to discovering this level of relationship.

4. Product Life Cycle --students should include a discussion of the impact of this subject matter. This is particularly appropriate given the growth stage of Details current products and the potential introduction stage if students recommend anything different in the product mix configuration of breadth and depth. The corresponding growth stage for their competitor offerings may also be incorporated as a component.

5. New Product Category -- If either the number of events (product lines/breadth) or offerings within the events (depth) are expanded in student recommendations the opportunity for students to provide a sense of their understanding of new product categories is feasible. This could include a basic distinction among imitative, replacement and innovative new product categories and the impact this may have on the ability to increase market share.

6. Market Share Allocation--students may be encouraged to consider the extent to which each product line contributes to the $15 \%-20 \%$ of the desired share. Students should recognize that to achieve this share, one or more of the competitors share would have to be reduced. A simple, yet effective approach is to demonstrate the percentages in the competitive profile totals $100 \%$ and that percentage is a constant. Students could also be asked to incorporate this as a component of one or more of the above report elements.

7. Product Position--it is important for students to understand that their recommendation should result in some feasible position(s) and that it should be clearly identified and justified in the report.

\section{CONCLUSION AND FUTURE RESEARCH}

As previously indicated, this paper has focused on the case study which evolved from the activities of an independent study completed by an undergraduate student. The development of this case, as previously discussed, has provided the professor with an evaluation instrument designed to provide a first level transition within a learning 
taxonomy for the introduction to marketing course. Equally important, the student engaged in the independent study was afforded the opportunity to not only investigate service marketing but to apply, analyze, and synthesize within a framework of the specific industry through a relevant corresponding occupational segment.

Subsequent to the development of this case the professor has engaged in additional research with another student to create a second corollary case. While the current case has concluded with the students considering the range of options available to pursue market expansion without any financial cost benefit analysis, the follow up case is intended to have a considerable quantitative orientation. The follow up case is being developed to provide the classroom instructor with the opportunity to demonstrate the financial challenges to expansion by focusing on projected changes in costs as well as the required changes in revenues necessary for break even when one of the potential solutions is chosen. This two step case process is being designed to enhance continuity of application and analysis among multiple elements of the marketing mix as the students continue to acquire course content throughout the academic semester.

\section{AUTHOR INFORMATION}

Professor Rosetti has been a full time faculty member of the Marketing and Management Department at Siena College since 1985. He has also served as the Assistant Dean of the School of Business and as Assistant Vice President of Academic Affairs at Siena, and it was in these capacities that he developed a background in learning assurance planning. He subsequently has published journal articles on pedagogy related topics and has presented national conference workshops on outcomes assessment. His primary teaching responsibilities include introduction to marketing, integrated marketing communications, and electronic/internet marketing.

Meghan Maceiko is a recent graduate of Siena College, earning a Bachelor of Science degree from the School of Business in Marketing and Management. During her undergraduate studies, she demonstrated a specific career interest in the event planning sector of service marketing. To extend her academic background in the subject matter, she pursued an independent study during her senior year which ultimately led to the collaboration of the case study incorporated in this journal article.

\section{BIBLIOGRAPHY}

1. Allen, Judy (2002), The Business of Event Planning, Wiley Publishing.

2. Bloom, Benjamin (1956), Taxonomy of educational objectives: Handbook I, The cognitive domain. et al.

3. Bonwell, Charles C. and James A. Eison (1991), "Active learning: Creating Excitement in the classroom." ASHE-ERIC Higher Education Report No. 1, Washington, D.C.: The George Washington University, School of Education and Human Development.

4. Kotler, Phillip (2008), Principles of Marketing, Prentice Hall Publishing.

5. Lamont, L.M. and Friedman, K. (1997), "Meeting the Challenges to Undergraduate Marketing Education", Journal of Marketing Education, Vol. 19, No. Fall, pp.17-30.

6. Lovelock, Christopher. (2000), Services Marketing, Prentice Hall Publishing.

7. Silberman, Mel (1990), Active Training, Lexington Books of MacMillan, Inc. Don Mills, Ontario.

8. Webster, Scott (2006), Principles and Tools for Supply Chain Management, McGraw-Hill Publishing.

9. Yin, Robert (2002), Applications of Case Study Research, Sage Publications.

10. Yin, Robert (2002), Case Study Research: Design and Methods, Sage Publications. 